\title{
Analysis by Vibrational Spectroscopy of Seaweed Polysaccharides with Potential Use in Food, Pharmaceutical, and Cosmetic Industries
}

\author{
Leonel Pereira, ${ }^{1}$ Saly F. Gheda, ${ }^{2}$ and Paulo J. A. Ribeiro-Claro ${ }^{3}$ \\ ${ }^{1}$ IMAR-CMA, Department of Life Sciences, FCTUC, University of Coimbra, 3004-516 Coimbra, Portugal \\ ${ }^{2}$ Phycology Lab., Botany Department, Faculty of Science, Tanta University, Tanta 31527, Egypt \\ ${ }^{3}$ Department of Chemistry, CICECO, University of Aveiro, 3810-193 Aveiro, Portugal
}

Correspondence should be addressed to Leonel Pereira; leonel@bot.uc.pt

Received 14 November 2012; Accepted 8 February 2013

Academic Editor: Otto Holst

Copyright (C) 2013 Leonel Pereira et al. This is an open access article distributed under the Creative Commons Attribution License, which permits unrestricted use, distribution, and reproduction in any medium, provided the original work is properly cited.

Polysaccharides present in several seaweeds (Kappaphycus alvarezii, Calliblepharis jubata, and Chondrus crispus-Gigartinales, Rhodophyta; Gelidium corneum and Pterocladiella capillacea-Gelidiales, Rhodophyta; Laurencia obtusa-Ceramiales, Rhodophyta; Himanthalia elongata, Undaria pinnatifida, Saccorhiza polyschides, Sargassum vulgare, and Padina pavonicaPhaeophyceae, Ochrophyta) are analyzed by spectroscopic techniques. The nature of the polysaccharides (with extraction and without any type of extraction) present in these seaweeds was determined with FTIR-ATR and FT-Raman analysis of extracted phycocolloids and ground dry seaweed.

\section{Introduction}

Many species of seaweed (marine macroalgae) are used as food and they have also found use in traditional medicine because of their perceived health benefits. Seaweeds are rich sources of sulphated polysaccharides, including some that have become valuable additives in the food industry because of their rheological properties as gelling and thickening agents (e.g., alginates, agar, and carrageenan). Sulphated polysaccharides are recognized to possess a number of biological activities including anticoagulant, antiviral, antitumor, anti-inflammatory, and immunostimulating activities that might find relevance in nutraceutical/functional food, cosmetic, and pharmaceutical applications [1].

Some seaweeds produce hydrocolloids, associated with the cell wall and intercellular spaces. Members of the red algae (Rhodophyta) produce galactans (e.g., carrageenans and agars) and the brown algae (Heterokontophyta, Phaeophyceae) produce uronates (alginates) and other sulphated polysaccharides (e.g., fucoidan and laminaran) [2-8].
The different phycocolloids used in food industry as natural additives are (European codes of phycocolloids)

(i) alginic acid-E400,

(ii) sodium alginate-E401,

(iii) potassium alginate-E402,

(iv) ammonium alginate-E403,

(v) calcium alginate-E404,

(vi) propylene glycol alginate-E405,

(vii) agar-E406,

(viii) carrageenan-E407,

(ix) semirefined carrageenan or "processed Eucheuma seaweed"-E407A.

Carrageenan and agar (Figure 1) are the principal sulphated polysaccharides produced by red seaweeds (Rhodophyta); 

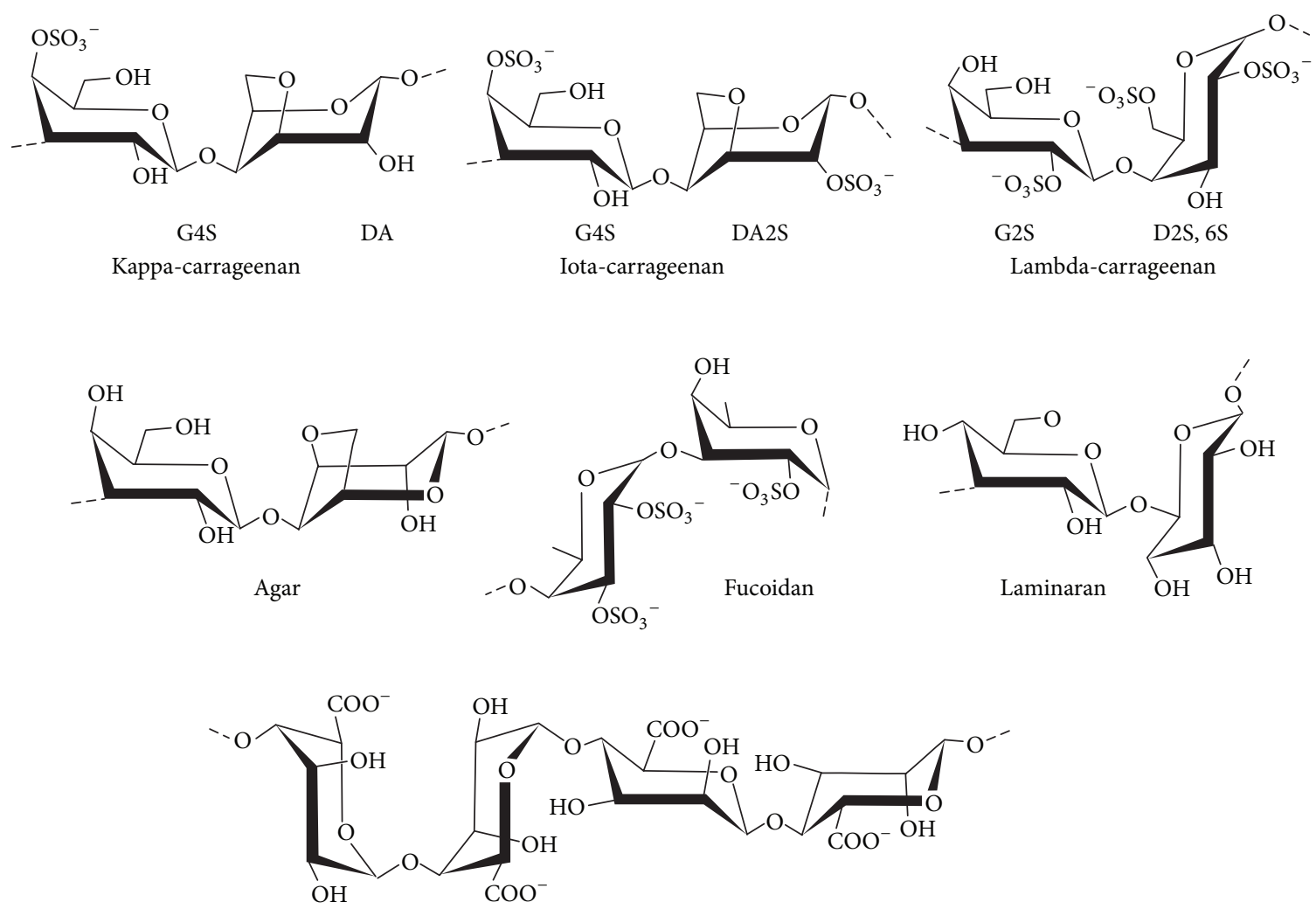

Alginic acid

FIGURE 1: Idealized structures of the chemical units of kappa-, iota-, and lambda-carrageenan, agar, alginic acid ( $\mathrm{M}=$ mannuronic acid and $\mathrm{G}=$ guluronic acid), fucoidan and laminaran $[13,14]$.

the main difference between the highly sulphated carrageenans from the less sulphated agars is the presence of Dgalactose and anhydro-D-galactose in carrageenans and of Dgalactose, L-galactose, or anhydro-L-galactose in agars.

The structure of the various types of carrageenans is defined by the number and position of sulphate groups, the presence of 3,6-anhydro-D-galactose, and conformation of the pyranose ring. There are about fifteen idealized carrageenan structures traditionally identified by Greek letters [9].

The commercial carrageenans are normally divided into three main types: kappa-, iota-, and lambda-carrageenans. Generally, seaweeds do not produce these idealized and pure carrageenans but more likely a range of hybrid structures. The precursors (mu and nu), when exposed to alkali conditions, are modified into kappa and iota, respectively, through formation of the 3,6-anhydrogalactose bridge [10].

Different types of carrageenan are obtained from different species of the Gigartinales (Rhodophyta). Kappacarrageenan is predominantly obtained by extraction from the cultivated tropical seaweed Kappaphycus alvarezii (known in the trade as "cottonii"). Eucheuma denticulatum (trade name "spinosum") is the main species for the production of iota-carrageenan. Lambda-carrageenan is obtained from different species from the genera Gigartina and Chondrus (trade name "Irish moss") [11].
The rheological properties of the gelling carrageenans (e.g., kappa and iota) are quite distinct: the kappa type forms gels that are hard, strong, and brittle, whereas iotacarrageenan forms soft and weak gels. The common feature of these carrageenans is the anhydrogalactose bridge of the 4linked galactose residue, DA and DA2S, respectively, which adopts the ${ }^{1} \mathrm{C}_{4}$-chair conformation. This conformation is crucial for the formation of the helical structure and, thereby, for the ability to form a gel. Lambda-carrageenan and the precursors mu- and nu-carrageenan lack the 3,6-anhydrobridge and, therefore, the 4 -linked residue adopts the ${ }^{4} C_{1}$-chair conformation, which disturbs the helical conformation. Thus, lambda-carrageenan acts simply as a thickening agent [11].

Agar (Figure 1) was the first colloid to be developed and it has applications as a gelling agent for food and also as an inert support medium for microbial culture. This polysaccharide is the dried hydrophilic, colloidal substance extracted commercially from certain marine algae of the phylum Rhodophyta. The most important commercial agarophyte genera are Gelidium, Pterocladiella, Gelidiella, and Gracilaria. Agar has also been found in species of Ceramium, Phyllophora, Ahnfeltia, Campylaephora, Acanthopholis, and Gracilariopsis. It is a polysaccharide, consisting primarily of D- and L-galactose units. About every tenth D-galactopyranose unit contains a sulphate ester group. Calcium, magnesium, potassium, or sodium cations are also 
associated with the polysaccharide. Agar may be separated into two fractions. One is a neutral polymer, agarose, composed of repeating units, referred to as agarobiose, and of alternating 1,3-linked $\beta$-D-galactopyranose and 1,4linked 3,6-anhydro- $\alpha$-L-galactopyranose. The second fraction has agaropectin, a more complicated structure. It contains residues of sulphuric, pyruvic, and uronic acids, in addition to D-galactose and 3,6-anhydro-L-galactose [10, 12].

Alginic acid (Figure 1) was discovered in 1883 by E. C. C. Stanford, a British pharmacist who called it algin. In seaweeds, algin is extracted as a mixed salt of sodium and/or potassium, calcium, and magnesium. The exact composition varies with algal species. Since Stanford discovered algin, the name has been applied to a number of substances, such as alginic acid and all alginates, derived from alginic acid. The extraction process is based on the conversion of an insoluble mixture of alginic acid salts of the cell wall in a soluble salt (alginate) which is appropriate for the water extraction [13-15]. This polysaccharide is derived from several genera of brown algae (e.g., mixed Fucales and Laminariales) that are utilized as raw materials by commercial alginate producers; these include Macrocystis, Laminaria, Lessonia, Ascophyllum, Alaria, Ecklonia, Eisenia, Nereocystis, Sargassum, Cystoseira and Fucus, with Macrocystis pyrifera and Ascophyllum nodosum being the principal sources of the world's alginate supply. The intercellular mucilage in these seaweeds has been regarded as the principal site of algin, although it has also been found to occur in the cell walls. Alginic acid is a complex organic compound composed of Dmannuronic acid and L-guluronic acid monomers [15-17].

Fucans (Figure 1) are sulphated polysaccharides that are composed of a fucose backbone. One of the best studied fucans from brown algae is fucoidan, which was first isolated by Kylin in 1913 [18]. The fucoidan from Fucus vesiculosus has been available commercially for decades (Sigma-Aldrich Chemical Company, St. Louis, MO, USA). Early work on its structure showed that it contained primarily $(1 \rightarrow 2)$ linked 4-O-sulphated fucopyranose residues. However, 3linked fucose with 4-sulphated groups were subsequently reported to be present on some of the fucose residues. Additionally, it was determined to contain branches every 2-3 fucose residues. Subsequently, Chevolot and colleagues reported that the fucoidan from F. vesiculosus and Ascophyllum nodosum contains a predominant disaccharide motif containing sulphate at the 2-position of the 3-linked fucose and sulphate groups on the 2- and 3-positions of the 4-linked fucose [19].

Laminaran (Figure 1) is a small glucan present in either soluble or insoluble forms. The first form is characterized by complete solubility in cold water, while the other is only soluble in hot water $[20,21]$. This polysaccharide is composed of D-glucose with b-(1,3) linkages, with b-(1,6) intrachain branching [6-8].

In this work, a combined FTIR-ATR and FT-Raman spectroscopy analysis was used to identify the main seaweed polysaccharides, namely, alginate, fucoidan, laminaran, agar, and kappa-, iota-, and lambda-carrageenans. Therefore, vibrational spectroscopy (FTIR-ATR and FT-Raman) is proposed as a useful tool for the cosmetic, pharmaceutical, and food industries to check the phycocolloid quality of a raw seaweed material by a quick and nondestructive method $[5,16]$.

\section{Materials and Methods}

2.1. Algal Material and Standard Samples of Hydrocolloids. Specimens of red algae (Rhodophyta) Kappaphycus alvarezii (Gigartinales) were collected in the Philippines. Specimens of red algae (Rhodophyta) Calliblepharis jubata, Chondrus crispus (Gigartinales), and Gelidium corneum (Gelidiales) and the brown algae (Phaeophyceae) Saccorhiza polyschides (Tilopteridales) were collected in the central zone of the western coast of Portugal. Pterocladiella capillacea (Gelidiales, Rhodophyta), Laurencia obtusa (Ceramiales, Rhodophyta), Padina pavonica (Dictyotales, Phaeophyceae), and Sargassum vulgare (Fucales, Phaeophyceae) were collected in the Mediterranean (Egypt). The edible brown seaweeds (Phaeophyceae) Himanthalia elongata (Fucales), and Undaria pinnatifida (Laminariales) were obtained from Algamar (Galicia, Spain).

Standard samples were obtained from Sigma (kappacarrageenan, type III, C-1263; iota-carrageenan, type V, C4014; alginic acid, A0682), TAAB Laboratories (agar, A010), and CP Kelco (pure lambda-carrageenan).

2.2. Preparation of Ground Seaweed Samples for FTIR-ATR and FT-Raman. The seaweed samples were rinsed in distilled freshwater to eliminate salt and debris from the thallus surface and dried to constant weight at $60^{\circ} \mathrm{C}$. The dried seaweeds were finely ground in order to render the samples uniform. For FTIR analysis the samples do not need additional treatment. The analysis by FT-Raman requires that these are without pigmentation. The lack of pigmentation can be achieved by sun drying (process used by collectors/producers of commercial seaweeds) or by pigment elimination in the laboratory by the addition of calcium hypochlorite solution $\left(4 \%, 30 / 60 \mathrm{~s}, 4^{\circ} \mathrm{C}\right)[5,16,22]$.

2.3. FTIR-ATR and FT-Raman Analysis. The FTIR spectra of sample materials (ground-dried seaweed, native and alkalimodified carrageenan) were recorded on an IFS 55 spectrometer, using a Golden Gate single reflection diamond ATR system, with no need for sample preparation. All spectra are the average of two independent measurements with 128 scans, each at a resolution of $2 \mathrm{~cm}^{-1}$.

The corresponding FT-Raman spectra were recorded on an RFS-100 Bruker FT-spectrometer using an Nd:YAG laser with an excitation wavelength of $1064 \mathrm{~nm}$. Each spectrum was the average of two repeated measurements, with 150 scans at a resolution of $2 \mathrm{~cm}^{-1}$.

\section{Results and Discussion}

The assignments of the IR spectra were mostly based on previous works $[4,5,9,16,23]$. The Raman spectra were assigned based on the IR information and on the comparison between samples of known composition. 


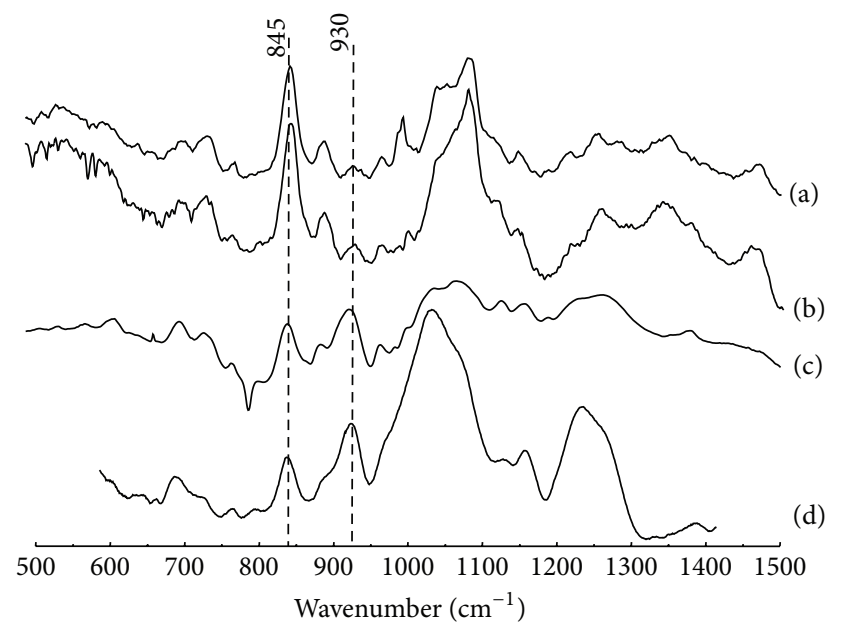

FIGURE 2: Spectra of commercial kappa-carrageenan and of ground seaweed sample (Kappaphycus alvarezii): FT-Raman ((a) and (b), resp.) and FTIR ((c) and (d), resp.).

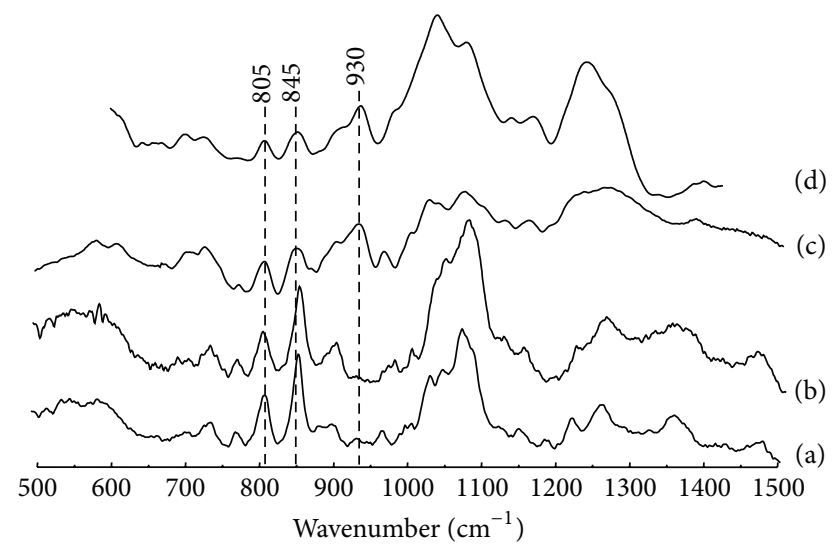

FIGURE 3: Spectra of commercial iota-carrageenan and of ground seaweed sample (Calliblepharis jubata): FT-Raman ((a) and (b), resp.) and FTIR ((c) and (d), resp.).

3.1. Identification of Carrageenan. The FTIR-ATR and FTRaman spectra of Kappaphycus alvarezii were compared with those of commercial kappa-carrageenan in Figure 2. The spectra of the ground seaweed show the main features of commercial kappa-carrageenan: a strong Raman band at approximately $845 \mathrm{~cm}^{-1}$ (with moderate intensity in the IR spectrum), which is assigned to D-galactose-4-sulphate (G4S) and a relatively strong band at approximately $930 \mathrm{~cm}^{-1}$ in the FTIR-ATR spectra, weak in FT-Raman spectrum, indicating the presence of 3,6-anhydro-D-galactose (DA) [5, 16 .

Figure 3 presents the FTIR-ATR and FT-Raman spectra of iota-carrageenan and of Calliblepharis jubata. The spectra of these samples also show the bands at approximately 930 and $845 \mathrm{~cm}^{-1}$, with the same intensity pattern as in kappacarrageenan. However, an additional well-defined feature is visible in both IR and Raman spectra, around $805 \mathrm{~cm}^{-1}$, indicating the presence of sulphate ester in the 2-position

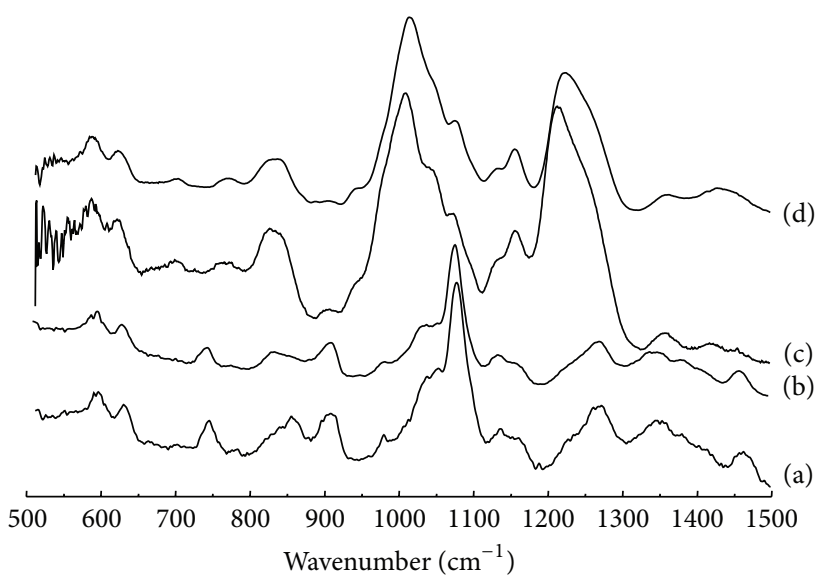

FIgURE 4: Spectra of commercial lambda-carrageenan and of ground seaweed sample (Chondrus crispus tetrasporophyte): FTRaman ((a) and (b), resp.) and FTIR ((c) and (d), resp.).

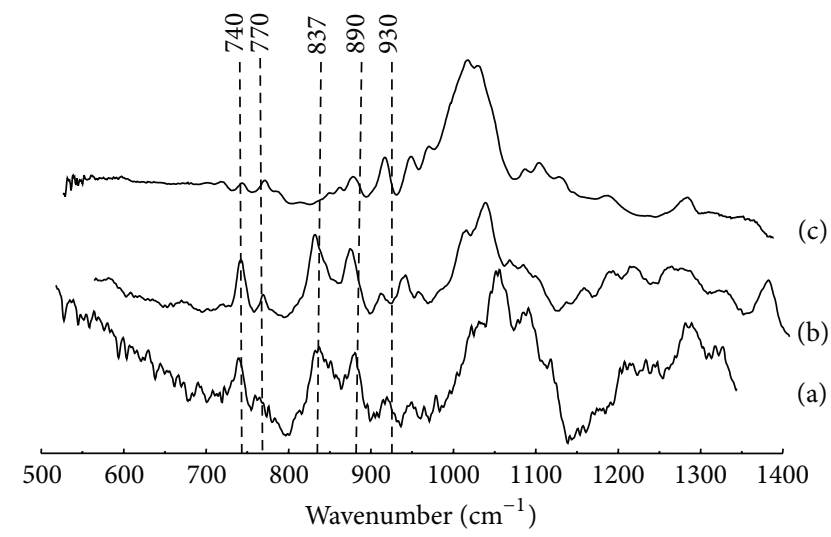

FIGURE 5: FT-Raman spectra of ground seaweed Gelidium corneum (a) and commercial agar (b) andFTIR-ATR spectra of ground seaweed Gelidium corneum (c).

of the anhydro-D-galactose residues (DA2S), a characteristic band of the iota-carrageenan $[5,16]$.

The FTIR-ATR and FT-Raman spectra of lambdacarrageenan and ground Chondrus crispus tetrasporophytes are shown in Figure 4. These samples present high sulphate content as indicated by the broad band between 820 and $830 \mathrm{~cm}^{-1}$ in FTIR-ATR spectra. The C. crispus and lambdacarrageenan FT-Raman spectra show the two combined weak bands between 815 and $830 \mathrm{~cm}^{-1}[5,16]$.

3.2. Identification of Agar. Agars differ from carrageenans as they have the L-configuration for the 4-linked galactose residue; nevertheless, they have some structural similarities with carrageenans. The characteristic broad band of sulphate esters in general [9] between 1210 to $1260 \mathrm{~cm}^{-1}$ (Figures 2, 3, and 4) was much stronger in carrageenan than in agar (Figures 5 and 6). Especially in the anomeric region $\left(700-950 \mathrm{~cm}^{-1}\right)$ agar and carrageenan showed several similar bands. Thus, the strong IR band at $930 \mathrm{~cm}^{-1}$ (Figures 5(c) and 


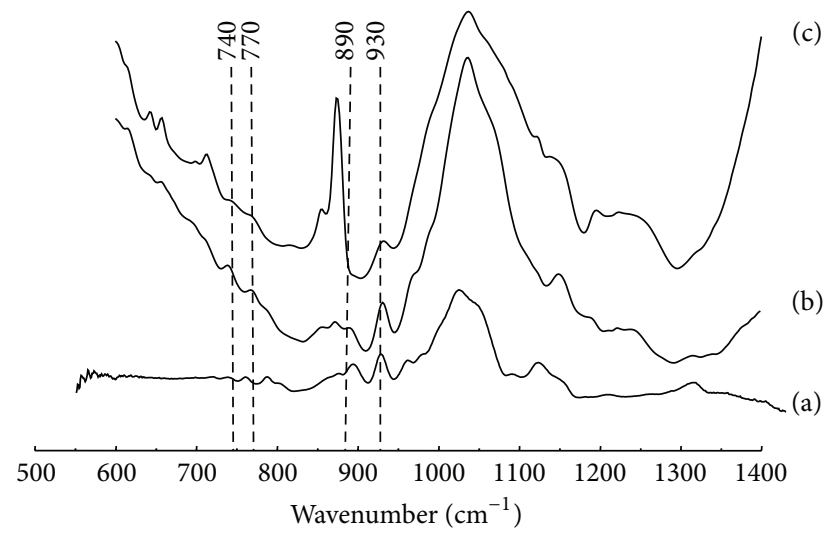

FIGURE 6: FTIR-ATR spectra of commercial agar (a), ground seaweed Pterocladiella capillacea (b), and Laurencia obtusa (c).

6(a)-6(c)) assigned to the presence of 3,6-anhydrogalactose was common to agar and carrageenans; the band at $890 \mathrm{~cm}^{-1}$ (Figures 5(a), 5(b), and 6) corresponded to anomeric $\mathrm{CH}$ of $\beta$-galactopyranosyl residues and Raman bands at 770, 740 (strong in the FT-Raman spectra and weak in the FTIR-ATR) are assigned to the skeleton bending of pyranose ring [23$25]$ both in agar and carrageenans. Also, the bands at 1010$1030 \mathrm{~cm}^{-1}$ (Figures 5(c) and 6(d)-6(f)) may be assigned to C$\mathrm{O}$ and $\mathrm{C}-\mathrm{C}$ stretching vibrations of pyranose ring common to all polysaccharides. So, the main polysaccharide composition of Gelidium corneum and of Pterocladiella capillacea is agar $[23,26,27]$.

The FT-Raman spectra (Figures 5(a) and 5(b)) show a strong band centred at $837 \mathrm{~cm}^{-1}$, which is absent in the FTIR spectra. After Matsuhiro [24], this band is associated with the $\mathrm{CH}$ vibration coupled with $\mathrm{C}-\mathrm{OH}$ related modes of $\alpha$ residues. Moreover, the spectral feature at $890 \mathrm{~cm}^{-1}$, also particularly intense in the FT-Raman spectra, is mainly associated with vibrational modes of the $\beta$-galactose residues.

Laurencia obtusa (Figure 6(f)) presents a complex agarlike sulphated galactan. These polysaccharides belong to the agar group, being agarose derivatives with a rather high content sulfate groups and with a reduced amount of 3,6anhydro-L-galactose residues $\left(700-950 \mathrm{~cm}^{-1}\right)$ [28].

3.3. Polysaccharides from Brown Algae. The main polysaccharide found in studied brown seaweeds (Phaeophyceae) was alginate, a linear copolymer of mannuronic (M) and guluronic acid $(\mathrm{G})$. Different types of alginic acid present different proportions and/or different alternating patterns of guluronic $(\mathrm{G})$ and mannuronic $(\mathrm{M})$ units. The presence of these acids can be identified from their characteristic bands in the vibrational spectra; in accordance with Mackie [25] these phycocolloids show two characteristic bands in IR spectra: $808 \mathrm{~cm}^{-1}$, assigned to $\mathrm{M}$ units, and $787 \mathrm{~cm}^{-1}$, assigned to $G$ units. However, Matsuhiro and coworkers, in work with specimens of Lessonia genus, assign both bands to $G$ units $[29,30]$. Filipov and Kohn [31] propose that $\mathrm{M} / \mathrm{G}$ ratios of the different samples can be estimated from

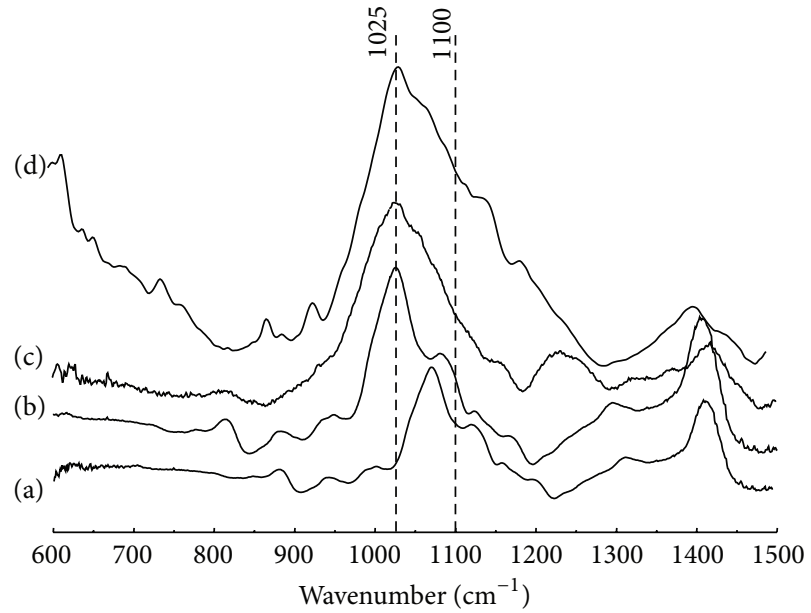

FIGURE 7: FT-Raman spectra of commercial alginate (a) and FTIR spectra of commercial alginate (b) and Saccorhiza polyschides (c). FTIR-ATR spectra of ground seaweed Himanthalia elongata (d).

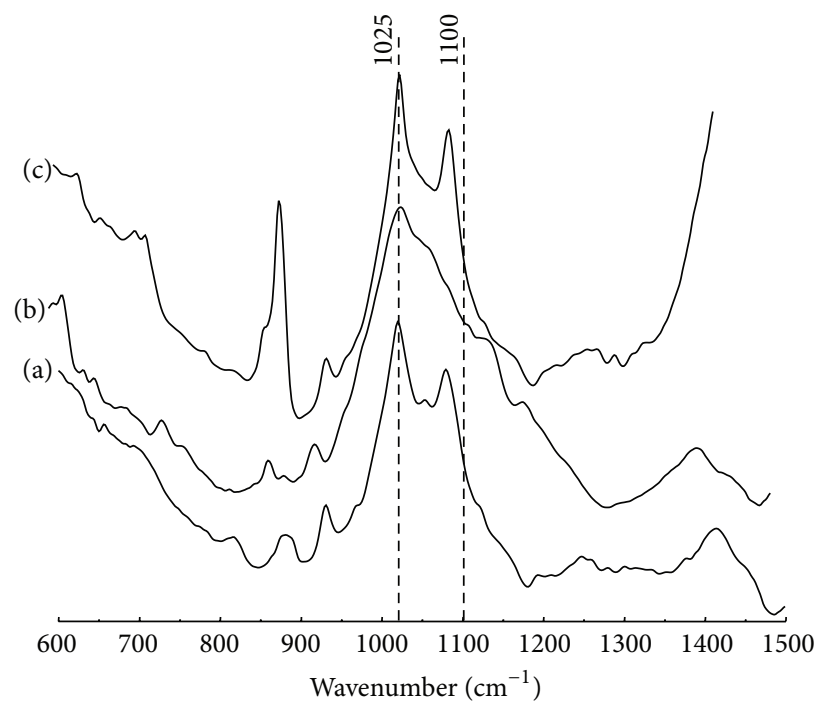

FIGURE 8: FTIR-ATR spectra of ground seaweed Undaria pinnatifida (a), Padina pavonica (b), and Sargassum vulgare (c).

the ratio of absorbance of the bands at 1320 and $1290 \mathrm{~cm}^{-1}$ in FTIR spectra. According to Sakugawa and collaborators [32] the $M / G$ concentration ratio characterizing a certain alginate sample can be inferred from the relative intensity ratio of the two bands $1030 / 1080 \mathrm{~cm}^{-1}$, in calcium alginate and $1019 / 1025 \mathrm{~cm}^{-1}$, in manganese alginate. In accordance with the same authors, the absorbance at $1030 \mathrm{~cm}^{-1}$ directly reflects the change of mannuronate concentration of calcium alginate and the $1025 \mathrm{~cm}^{-1}$ is attributed to the $\mathrm{OH}$ bending of guluronate [32].

Alginate $\mathrm{M} / \mathrm{G}$ ratio was tentatively estimated from the $1030 / 1080 \mathrm{~cm}^{-1}$ band ratio in infrared spectra, suggesting higher values of mannuronic than guluronic acid blocks $(\mathrm{M} / \mathrm{G}>1)$ in Himanthalia elongata (Figure $7(\mathrm{~d})$ ). However, the FTIR spectra of Saccorhiza polyschides (Figure 7(c)) show 
an intense broad band centred at $1025 \mathrm{~cm}^{-1}$, indicating that the samples considered are particularly rich in guluronic acid. According to our spectrum on U. pinnatifida (old adult thallus, Figure $8(\mathrm{a})$ ), the relative amounts of both mannuronate and guluronate residues were similar, and result in accordance with other published works [33].

Our spectra suggesting higher values of guluronic than mannuronic acid blocks in Padina pavonica (Figure 8(b)); Sargassum vulgare spectra (Figure 8(c)) suggesting the presence of similar amounts of the mannuronate and guluronate residues, results in accordance with other published works [33-35].

Some brown algae (see Figures 7(c) and 8(a), Saccorhiza polyschides and Undaria pinnatifida, resp.) also exhibited a broad band around $1220-1260 \mathrm{~cm}^{-1}$, assigned to the presence of sulphate ester groups $(\mathrm{S}=\mathrm{O})$ which is a characteristic component in fucoidan and sulphated polysaccharides other than alginate in brown seaweeds. Padina pavonica and Sargassum vulgare (see Figures 8(b) and 8(c)) also exhibited a broad band (around $1195-1237 \mathrm{~cm}^{-1}$ for Padina and 1210$1280 \mathrm{~cm}^{-1}$ for Sargassum) assigned to $(\mathrm{S}=\mathrm{O})$ which is characteristic component in fucoidan (main water soluble sulphated polysaccharide); however, Sargassum vulgare contains more amounts of fucoidan than in Padina pavonica, whereas, both seaweed species contain little amounts of laminaran [2, 6$8,20,21,36]$.

\section{Conclusion}

Vibrational FTIR-ATR spectroscopy (FTIR-ATR and FTRaman) is a useful tool in the food, pharmaceutical, and cosmetics industries for a preliminary identification of the main sulphated polysaccharides (namely, alginate, laminaran, fucoidan, agar, and carrageenan) produced by edible brown and red seaweeds, by a rapid and non-destructive method.

\section{Acknowledgments}

The authors acknowledge financial support from the Portuguese Foundation for Science and Technology-IMARCMA (Institute of Marine Research) and Laboratório Associado CICECO.

\section{References}

[1] L. Pereira, "A Review of the nutrient composition of selected edible seaweeds," in Seaweed: Ecology, Nutrient Composition and Medicinal Uses, V. H. Pomin, Ed., pp. 15-47, Nova Science, New York, NY, USA, 2011.

[2] G. Jiao, G. Yu, J. Zhang, and H. S. Ewart, "Chemical structures and bioactivities of sulfated polysaccharides from marine algae," Marine Drugs, vol. 9, no. 2, pp. 196-233, 2011.

[3] B. Rudolph, "Seaweed products: red algae of economic significance," in Marine \& Freshwater Products Handbook, R. E. Martin, Ed., pp. 515-529, Technomic, Lancaster, UK, 2000.

[4] L. Pereira and F. van de Velde, "Portuguese carrageenophytes: carrageenan composition and geographic distribution of eight species (Gigartinales, Rhodophyta)," Carbohydrate Polymers, vol. 84, no. 1, pp. 614-623, 2011.
[5] L. Pereira, A. M. Amado, A. T. Critchley, F. van de Velde, and P. J. A. Ribeiro-Claro, "Identification of selected seaweed polysaccharides (phycocolloids) by vibrational spectroscopy (FTIR-ATR and FT-Raman)," Food Hydrocolloids, vol. 23, no. 7, pp. 1903-1909, 2009.

[6] L.-E. Rioux, S. L. Turgeon, and M. Beaulieu, "Structural characterization of laminaran and galactofucan extracted from the brown seaweed Saccharina longicruris," Phytochemistry, vol. 71, no. 13, pp. 1586-1595, 2010.

[7] V. Barry, "Constitution of laminarin-isolation of 2, 4, 6trimethylglucopyranose," Scientific Proceedings of Royal Dublin Society, no. 22, pp. 59-67, 1939.

[8] S. Peat, W. J. Whelan, and H. G. Lawley, "The structure of laminarin. Part I. The main polymeric linkage," Journal of the Chemical Society, pp. 724-728, 1958.

[9] T. Chopin, B. F. Kerin, and R. Mazerolle, "Phycocolloid chemistry as a taxonomic indicator of phylogeny in the Gigartinales, Rhodophyceae: a review and current developments using Fourier transform infrared diffuse reflectance spectroscopy," Phycological Research, vol. 47, no. 3, pp. 167-188, 1999.

[10] H. J. Bixler and H. Porse, "A decade of change in the seaweed hydrocolloids industry," Journal of Applied Phycology, vol. 23, no. 3, pp. 321-335, 2011.

[11] F. van de Velde and G. A. de Ruiter, "Carrageenan," in Biopolymers V. 6. Polysaccharides II, Polysaccharides from Eukaryotes, E. J. Vandamme, S. D. Baets, and A. Steinbèuchel, Eds., pp. 245274, Wiley-VCH, Chichester, UK, 2002.

[12] M. Lahaye, "Developments on gelling algal galactans, their structure and physico-chemistry," Journal of Applied Phycology, vol. 13, no. 2, pp. 173-184, 2001.

[13] C. S. Lobban, D. J. Chapman, and B. P. Kremer, Experimental Phycology: A Laboratory Manual, Phycological Society of America, Cambridge University Press, 1988.

[14] M. Lahaye, "Chemistry and physico-chemistry of phycocolloids," Cahiers de Biologie Marine, vol. 42, no. 1-2, pp. 137-157, 2001.

[15] M. Rinaudo, "Alginates and carrageenans," Actualite Chimique, no. 11-12, pp. 35-38, 2002.

[16] L. Pereira, Estudos em macroalgas carragenófitas (Gigartinales, Rhodophyceae) da costa portuguesa-aspectos ecológicos, bioquímicos e citológicos [Ph.D. thesis], FCTUC, University of Coimbra, 2004.

[17] C. Sartori, D. S. Finch, B. Ralph, and K. Gilding, "Determination of the cation content of alginate thin films by FTi.r. Spectroscopy," Polymer, vol. 38, no. 1, pp. 43-51, 1997.

[18] H. Kylin, "Biochemistry of sea algae," Zeitschrift für Physikalische Chemie, vol. 83, pp. 171-197, 1913.

[19] L. Chevolot, B. Mulloy, J. Ratiskol, A. Foucault, and S. ColliecJouault, "A disaccharide repeat unit is the major structure in fucoidans from two species of brown algae," Carbohydrate Research, vol. 330, no. 4, pp. 529-535, 2001.

[20] A. O. Chizhov, A. Dell, H. R. Morris et al., "Structural analysis of laminarans by MALDI and FAB mass spectrometry," Carbohydrate Research, vol. 310, no. 3, pp. 203-210, 1998.

[21] T. E. Nelson and B. A. Lewis, "Separation and characterization of the soluble and insoluble components of insoluble laminaran," Carbohydrate Research, vol. 33, no. 1, pp. 63-74, 1974.

[22] M. Zinoun and J. Cosson, "Seasonal variation in growth and carrageenan content of Calliblepharis jubata (Rhodophyceae, Gigartinales) from the Normandy coast, France," Journal of Applied Phycology, vol. 8, no. 1, pp. 29-34, 1996. 
[23] L. Pereira, A. Sousa, H. Coelho, A. M. Amado, and P. J. A. Ribeiro-Claro, "Use of FTIR, FT-Raman and ${ }^{13} \mathrm{C}-\mathrm{NMR}$ spectroscopy for identification of some seaweed phycocolloids," Biomolecular Engineering, vol. 20, no. 4-6, pp. 223-228, 2003.

[24] B. Matsuhiro, "Vibrational spectroscopy of seaweed galactans," Hydrobiologia, vol. 326-327, pp. 481-489, 1996.

[25] W. Mackie, "Semi-quantitative estimation of the composition of alginates by infra-red spectroscopy," Carbohydrate Research, vol. 20, no. 2, pp. 413-415, 1971.

[26] E. Gómez-Ordóñez and P. Rupérez, "FTIR-ATR spectroscopy as a tool for polysaccharide identification in edible brown and red seaweeds," Food Hydrocolloids, vol. 25, no. 6, pp. 1514-1520, 2011.

[27] M. Sekkal, P. Legrand, J. P. Huvenne, and M. C. Verdus, “The use of FTIR microspectrometry as a new tool for the identification in situ of polygalactanes in red seaweeds," Journal of Molecular Structure, vol. 294, pp. 227-230, 1993.

[28] A. I. Usov and M. Y. Elashvili, "Polysaccharides of algae. 44. Investigation of sulfated galactan from Laurencia nipponica Yamada (Rhodophyta, Rhodomelaceae) using partial reductive hydrolysis," Botanica Marina, no. 34, pp. 553-560, 1991.

[29] N. P. Chandia, B. Matsuhiro, and A. E. Vasquez, "Alginic acids in Lessonia trabeculata: characterization by formic acid hydrolysis and FT-IR spectroscopy," Carbohydrate Polymers, vol. 46, no. 1, pp. 81-87, 2001.

[30] N. P. Chandía, B. Matsuhiro, E. Mejías, and A. Moenne, "Alginic acids in Lessonia vadosa: partial hydrolysis and elicitor properties of the polymannuronic acid fraction," Journal of Applied Phycology, vol. 16, no. 2, pp. 127-133, 2004.

[31] M. P. Filippov and R. Kohn, "Determination of composition of alginates by infra-red spectroscopic methods," Chemické Zvesti, no. 28, p. $817,1974$.

[32] K. Sakugawa, A. Ikeda, A. Takemura, and H. Ono, "Simplified method for estimation of composition of alginates by FTIR," Journal of Applied Polymer Science, vol. 93, no. 3, pp. 1372-1377, 2004.

[33] A. Skriptsova, V. Khomenko, and I. Isakov, "Seasonal changes in growth rate, morphology and alginate content in Undaria pinnatifida at the northern limit in the Sea of Japan (Russia)," Journal of Applied Phycology, vol. 16, no. 1, pp. 17-21, 2004.

[34] M. R. Torres, A. P. A. Sousa, E. A. T. Silva Filho et al., "Extraction and physicochemical characterization of Sargassum vulgare alginate from Brazil," Carbohydrate Research, vol. 342, no. 14, pp. 2067-2074, 2007.

[35] K. Sahayaraj, S. Rajesh, and J. M. Rathi, "Silver nanoparticles biosynthesis using marine alga Padina pavonica (Linn.) and its microbicidal activity," Digest Journal of Nanomaterials and Biostructures, no. 7, pp. 1557-1567, 2012.

[36] N. P. Chandía and B. Matsuhiro, "Characterization of a fucoidan from Lessonia vadosa (Phaeophyta) and its anticoagulant and elicitor properties," International Journal of Biological Macromolecules, vol. 42, no. 3, pp. 235-240, 2008. 

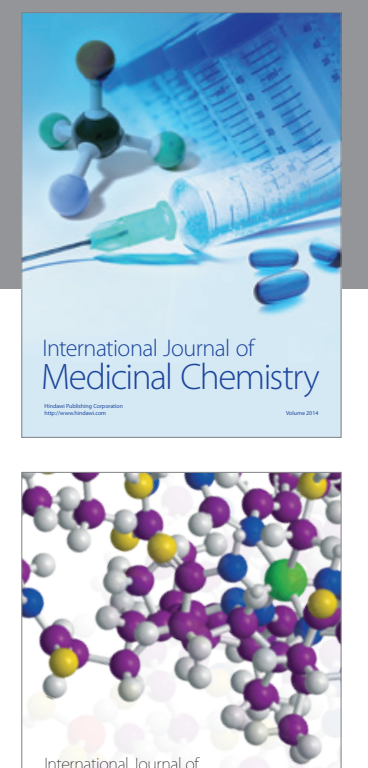

\section{Carbohydrate} Chemistry

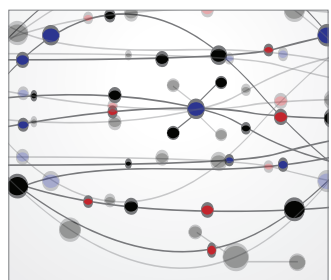

The Scientific World Journal
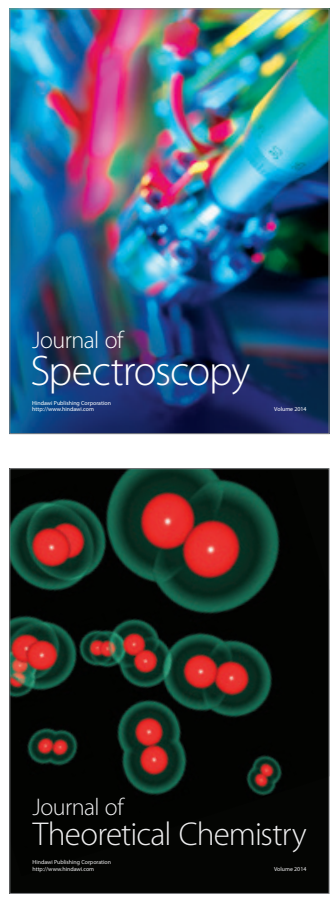
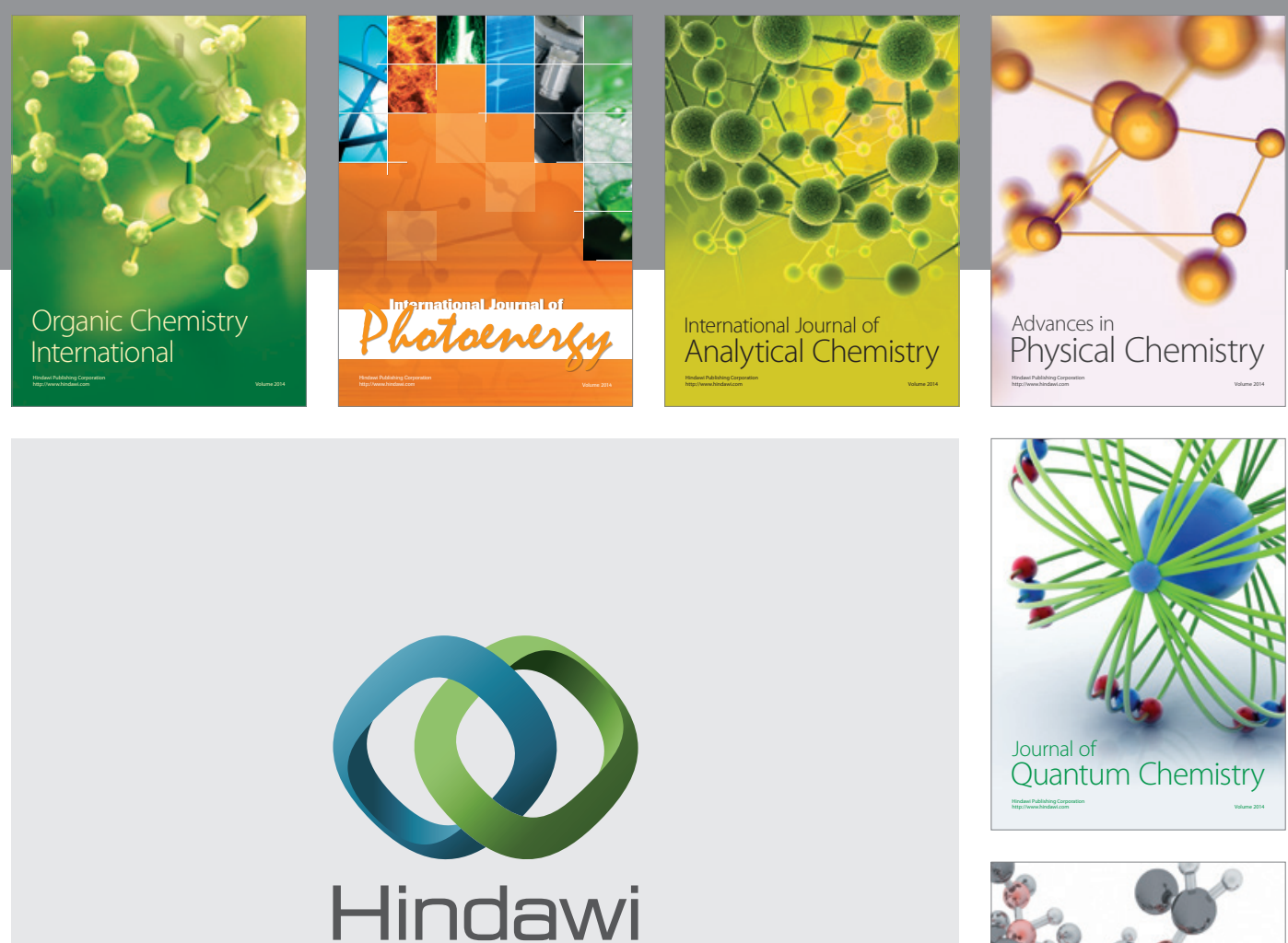

Submit your manuscripts at

http://www.hindawi.com

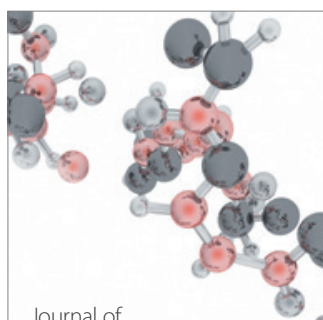

Analytical Methods

in Chemistry

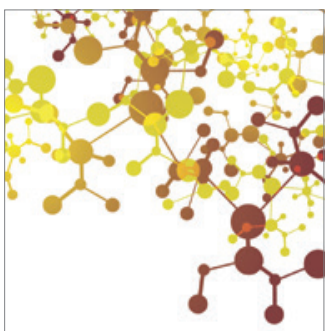

Journal of

Applied Chemistry

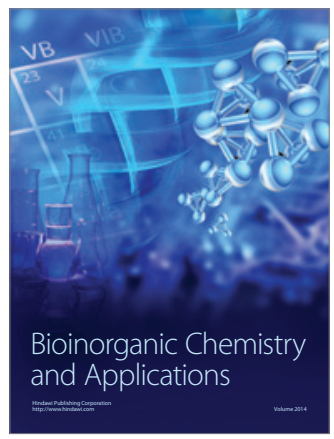

Inorganic Chemistry
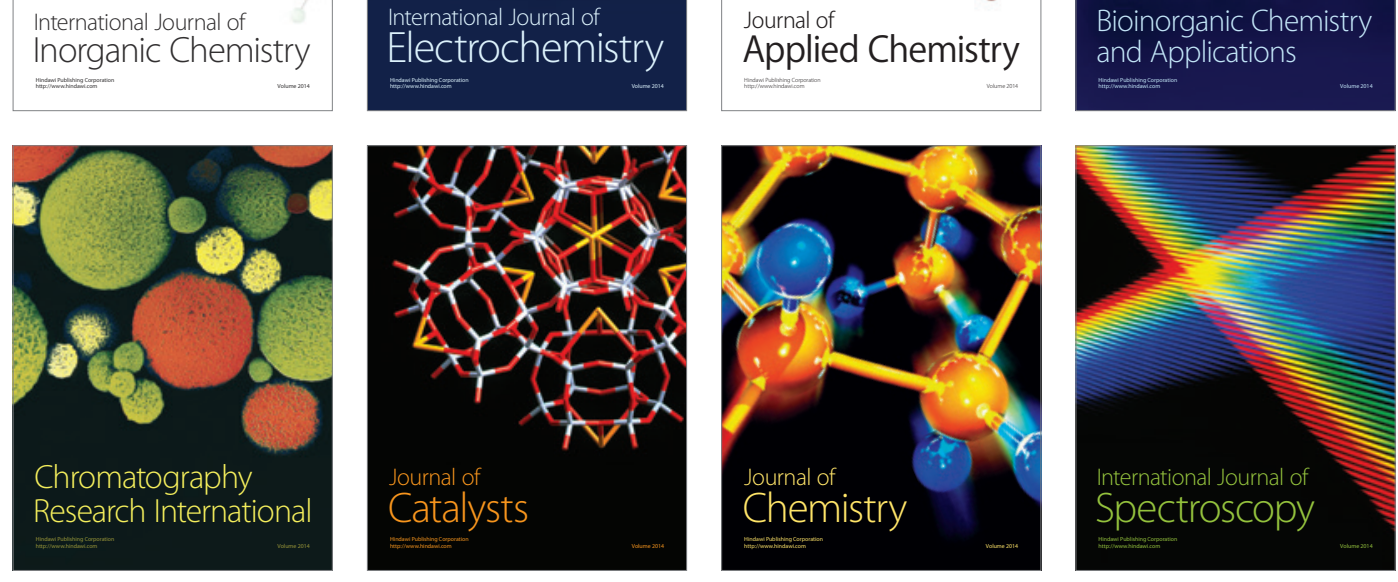